\title{
Integrale zorg: ervaringen en opvattingen van huisartsen
}

\author{
Ruben D. Scheffer - Maria E. T. C. van den Muijsenbergh
}

Published online: 5 February 2019

(c) The Author(s) 2019

\begin{abstract}
Samenvatting
Achtergrond Sociaal kwetsbare patiënten bezoeken de huisarts vaak met lichamelijke klachten die gerelateerd zijn aan psychosociale problemen. Effectieve zorg hiervoor integreert medische zorg met zorg op psychisch en sociaal terrein. Het is evenwel niet bekend hoe huisartsen denken over zulke integrale zorg en hoe zij hun rol zien ten aanzien van de sociale problemen van hun patiënten. Het doel van dit onderzoek is vergroting van inzicht in de opvattingen over, ervaringen met en aanbevelingen van huisartsen met betrekking tot integrale zorg voor hun sociaal kwetsbare populatie.

Methode Een kwalitatief onderzoek met semigestructureerde interviews met twaalf huisartsen verspreid door Nederland, die thematisch geanalyseerd zijn.

Resultaten Aandacht voor sociale problemen is een essentieel onderdeel van de huisartsenzorg. Huisartsen achten integrale multidisciplinaire zorg noodzakelijk om deze problemen, die vaak samenhangen met lichamelijke en psychische problemen, effectief aan te pakken. Zij zien voor zichzelf een coördinerende en verbindende rol, waarbij de invulling per huisarts varieert. Hun belangrijkste samenwerkingspartners zijn de praktijkondersteuner-ggz en wijkverpleegkundige. Als belangrijkste belemmeringen voor integrale zorg ervaren zij gebrek aan tijd voor patiëntencontact en samenwerking, en aan vaardigheden om op maat te communiceren met laaggeletterden en migranten.
\end{abstract}

R. D. Scheffer · M. E. T. C. van den Muijsenbergh ( $\square)$ Afdeling Eerstelijnsgeneeskunde, Radboudumc, Nijmegen, Nederland

maria.vandenmuijsenbergh@radboudumc.nl

M. E. T. C. van den Muijsenbergh

Pharos, expertisecentrum gezondheidsverschillen, Utrecht, Nederland
Conclusie Huisartsen rekenen integrale zorg tot hun taken, waarbij multidisciplinaire samenwerking cruciaal is. Hiervoor hebben zij meer tijd en training nodig.

Trefwoorden integrale zorg - huisartsen - sociaal kwetsbare groepen $\cdot$ samenwerking

\section{Integrated care: experiences and opinions of general practitioners}

\begin{abstract}
Background Socially vulnerable patients visit the general practitioner (GP) often with physical complaints related to social problems. For this, effective care integrates medical care with mental health and social care. However, it is yet unknown how GPs think about such integrated care and their role regarding social problems. The object of this study is to get insight into ideas, experiences and recommendations of GPs about integrated care for their socially vulnerable population.

Methods A qualitative study consisting of semi-structured interviews with twelve GPs in the Netherlands, thematically analyzed.

Results Attending to social problems is an essential element of GP-care. GPs think integrated multidisciplinary care is necessary to solve these social problems, that are interdependent with physical and mental health problems. They all see their role as coordinating and connecting, the actual execution differing between GPs. Their main partners are the mental health nurse in GP and the community health nurse. They experience obstacles to perform integrated care, especially a lack of time, for patient contacts and collaboration, and of skills to communicate effectively with migrants and low literate patients.
\end{abstract}




\section{Kernpunten}

- Psychosociale problemen, vooral bij mensen met een lage sociaaleconomische status, vormen volgens huisartsen een onlosmakelijk onderdeel van de huisartsenzorg.

- Huisartsen willen de 'spin in het web' zijn en integrale zorg leveren die effectief is voor deze problemen.

- Hiervoor zijn meer tijd en training nodig, en is goede samenwerking met andere disciplines cruciaal.

Conclusion GPs see integrated care as their job and multidisciplinary collaboration as essential to make this effective. They need more time and training.

Keywords integrated care $\cdot$ general practitioners $\cdot$ socially vulnerable groups $\cdot$ cooperation

\section{Inleiding}

Sociaaleconomische gezondheidsverschillen zijn de systematische verschillen in gezondheid tussen mensen met een hoge en lage sociale status, afgemeten aan opleiding en inkomen. Deze verschillen worden versterkt door een eventuele migratieachtergrond [1-3]. Ongunstige sociale omstandigheden, die veel vaker voorkomen bij mensen met een lage sociale status, zoals armoede, eenzaamheid [4] en sociale uitsluiting, leiden via het mechanisme van chronische stress tot een grotere kans op ziekten (hartvaatziekten, diabetes, depressies) en tot een ongezonde leefstijl.

Daarbij komt nog dat de organisatie van onze gezondheidszorg complex is en informatie over gezondheid voor ongeveer $29 \%$ van de Nederlandse bevolking onbegrijpelijk of niet toepasbaar is [5]. Dit betreft laaggeletterden [6] en veel migranten [7]. We duiden in dit artikel alle groepen mensen met beperkte gezondheidsvaardigheden en een lage sociale positie aan met de term 'sociaal kwetsbare groepen'. Maatschappelijke ongelijkheid leidt zo niet alleen tot een grotere kans op ziekte, maar ook tot slechtere uitkomsten van medische zorg [8-11].

Voor de bestrijding en zeker preventie van deze ziekten, gerelateerd aan sociale omstandigheden, moet medische zorg dus samengaan met sociale zorg: pillen en het advies om af te vallen zijn onvoldoende voor de patiënt met chronische stress door schulden. Zo'n benadering, die aandacht schenkt aan zowel lichamelijke als psychische en sociale problemen en omstandigheden, wordt integrale zorg genoemd en kan doorgaans niet door één discipline worden geleverd [12].

Huisartsen verkeren in een unieke positie om bij te dragen aan het verminderen van deze sociaaleconomische gezondheidsverschillen [13]. Zij komen thuis bij mensen en zien de soms desastreuze gevolgen van sociale misstanden, zoals armoede, slechte huisvesting, fysiek of psychisch geweld en andere bronnen van chronische stress. Een sterke eerstelijnszorg is wereldwijd geassocieerd met een betere toegang tot de zorg, en betere kwaliteit en uitkomsten van zorg, vooral voor sociaal kwetsbare groepen [14-16].

Ook uit diverse registraties blijkt dat sociaal kwetsbare patiënten de huisarts vaak bezoeken met lichamelijke klachten die gerelateerd zijn aan psychosociale problemen [17-19]. Een adequate aanpak van hun klachten en problemen vergt dus niet alleen biomedische aandacht, waarin de huisarts specifiek is opgeleid, maar ook aandacht voor de psychosociale situatie, oftewel de integrale zorg zoals hierboven beschreven.

Een dergelijke integrale en dus multidisciplinaire zorg vraagt veel van de huisarts, zowel van de eigen gespreksvaardigheden (het boven tafel krijgen van de problemen op verschillen gebieden), als van samenwerkingsvaardigheden ten behoeve van de samenwerking met professionals uit het sociale domein, zoals het sociaal wijkteam [20]. Het is evenwel niet bekend wat huisartsen eigenlijk vinden van integrale zorg, hoe zij hun rol zien, wat ze doen om integrale zorg te leveren en voor welke uitdagingen ze daarbij komen te staan. Inzicht in deze opvattingen en ervaringen kan helpen bij het vormgeven van integrale zorg, die nodig is voor de ondersteuning van sociaal kwetsbare groepen en het terugdringen van gezondheidsverschillen. Dit onderzoek wil bijdragen aan dit inzicht.

\section{Methode}

\section{Onderzoeksontwerp}

Door middel van semigestructureerde interviews met huisartsen wilden we inzicht krijgen in ervaringen, opvattingen en aanbevelingen van huisartsen over integrale zorg.

\section{Onderzoekspopulatie en werving}

Het onderzoek vond plaats in 2018. Via purposeful sampling werden huisartsen geïncludeerd, zowel met veel als met weinig ervaring met sociaal kwetsbare groepen. Variatie is nagestreefd in leeftijd, gender en geografische locatie van de praktijk (platteland, grote en kleine stad). Inclusie ging door tot theoretische verzadiging was bereikt.

\section{Gegevensverzameling en -analyse}

Een topic list werd samengesteld op basis van literatuur en expert opinion. Bij het interview werd gekozen voor de insteek van herkenbare problematiek van de huisarts, namelijk de zorg voor sociaal kwetsbare mensen met sociale problemen. Vervolgens werd ingezoomd op 'integrale zorg', die de multidisciplinaire zorg betreft die aandacht schenkt aan zowel biomedi- 
Tabel 1 Kenmerken van respondenten

\begin{tabular}{|l|l|l|l|l|}
\hline & Man/vrouw & Aantal jaren werkzaam als huisarts & Migratieachtergrond & \multicolumn{1}{l|}{ Plaats van de praktijk } \\
\hline 1 & man & 20 & nee & Utrecht \\
\hline 2 & vrouw & 38 & nee & Rotterdam \\
\hline 3 & man & 12 & ja & nee \\
\hline 4 & vrouw & 27 & nee & Leiden \\
\hline 5 & vrouw & $3 e$ jaar huisartsenopleiding & nee & Leiden \\
\hline 6 & man & 6 & nee & Dorp in Oost-Nederland \\
\hline 7 & man & 30 & nee & Nijmegen \\
\hline 8 & man & 4 & ja & Klein dorp in Oost- Nederland \\
\hline 9 & man & 2 & ja & Tilburg \\
\hline 10 & man & 2 & nee & Den Haag \\
\hline 11 & vrouw & 21 & nee & Amsterdam \\
\hline 12 & vrouw & 24 & & Nijmegen \\
\hline
\end{tabular}

sche (lichamelijke), als psychische en sociale problemen en omstandigheden. Onderwerpen van gesprek waren:

- ervaringen met sociaal kwetsbare patiënten met sociale problemen;

- opsporen/herkennen van deze problemen; hierbij werd expliciet gevraagd naar hun ervaring met een aantal instrumenten dat ontwikkeld is voor huisartsen om problemen van patiënten breed in kaart te brengen - dus zowel medisch als psychisch en sociaal. Zo is er het 4D-model [21], ontwikkeld door huisartsen in Utrecht, het 'spinnenweb' -gespreksinstrument op basis van het concept positieve gezondheid [22], dat zes dimensies onderscheidt, en de zelfredzaamheidsmatrix [23], ontwikkeld door GGD Amsterdam en Rotterdam, en wordt in het medisch communicatieonderwijs de anamnese volgens het SCEGS (Somatiek Cognitie Emotie Gedrag Sociaal) model aangeleerd;

- de rol van de huisarts bij de aanpak van deze problemen;

- samenwerking met partners in de wijk en het sociale domein;

- het belang van integrale zorg;

- belemmeringen en voorwaarden om integrale zorg te leveren.

De eerste auteur, bijna afgestudeerd arts, nam de interviews af, die werden opgenomen op audiotape, en verbatim getranscribeerd en gecodeerd met hulp van softwareprogramma Atlas.ti. De eerste drie interviews werden door de twee auteurs onafhankelijk van elkaar gecodeerd. Ze vergeleken en bespraken de codes tot ze overeenstemming over de duiding hadden bereikt. De codes werden gegroepeerd tot categorieën en thematisch geanalyseerd.

\section{Resultaten}

$\mathrm{Na}$ twaalf interviews was theoretische saturatie bereikt. De respondenten varieerden in leeftijd, ervaring (van huisarts in opleiding tot 38 jaar ervaring), migratieachtergrond en geografische locatie (zie tab. 1).

\section{Sociale problemen horen bij de huisartsenzorg}

Alle huisartsen hebben te maken met patiënten met sociale problemen en zijn van mening dat het tot hun taak hoort hier iets mee te doen.

'Je kunt wel zeggen dat je als huisarts niets te maken hebt met psychosociale problemen, maar in de praktijk is dat gewoon niet mogelijk.' (HA 2)

Een grote verscheidenheid aan psychosociale problemen en sociaaleconomische achterstanden dient zich aan in de huisartsenpraktijk. Het vaakst werden financiële, huisvestings- en relatieproblemen genoemd. Daarnaast werden geregeld genoemd: huiselijk geweld, psychiatrische problemen en opvoedingsproblemen - waarbij vaak sprake is van een combinatie.

'Het ene probleem lokt het volgende uit.' (HA 4)

\section{Onderlinge samenhang tussen lichamelijke, psychische en sociale problemen}

Elf van de twaalf huisartsen gaven aan dat lichamelijke, psychische en sociale problemen met elkaar samenhangen. Dat zien zij bij alle patiënten, maar sociaal kwetsbare patiënten (door de huisartsen aangeduid als 'lage SES' of 'achterstandsgroepen') hebben meer problemen op meerdere terreinen en vinden het vaak moelijker om te onderscheiden op welk terrein een probleem ligt.

'In de ogen van de dokter hangen deze problemen samen, ja, maar die samenhang is er niet in de ogen van de patiënten. Zij komen met lichamelijke klachten die wij verbinden aan psychosociale problemen. De patiënt wil aandacht voor dat lichamelijke.' (HA 6) 
'De uitdaging is om de lichamelijke klachten te decoderen naar hun oorsprong en daar de oplossing te zoeken.' (HA 7)

\section{Actief vragen naar sociale problemen}

De meerderheid van de huisartsen vertelde actief naar sociale problemen te vragen, vooral op het gebied van financiën, huisvesting en eenzaamheid. Bovendien denken ze bij bepaalde klachten sneller aan een samenhang met sociale problemen. Het vaakst noemden ze hierbij hoofdpijn, gespannenheid, moeheid, rugpijn en somatisch onvoldoende verklaarde klachten.

'Ik heb een antenne ontwikkeld voor psychosociale problemen, als een bepaalde behandeling niet aanslaat. Vroeger dacht ik dat de klacht therapieresistent was of dat de patiënt de adviezen niet opvolgde. $\mathrm{Nu}$ denk ik dan dat er iets anders speelt.' (HA 1)

'Je moet zoeken naar een ingang om met iemand verder te komen. Als huisarts moet je het puur medische deel even opzij zetten, want daar moet je pas met een paar omwegen bij komen.' (HA 7)

'Ik kies ervoor uit mijn spreekkamer te komen. Ik zie de mensen in de gang, in mijn wachtkamer. Ik zie wat ze aanhebben, ik ruik hen. Mijn eerste primaire analyse begint daar.' (HA 10)

Gevraagd naar de verschillende hulpmiddelen om de domeinen van lichamelijke, psychische en sociale problemen te onderscheiden bleek dat de meeste huisartsen het 4D-model kenden, en dat een aantal van hen het ook gebruikte. Zij vonden dit erg lijken op de SCEGS, waarmee zij allen bekend waren, en zagen verband met het concept positieve gezondheid van Machteld Hueber. Het op dit laatste model geënte 'spinnenweb'-gespreksinstrument gebruikten ze niet.

De huisartsen waren blij met deze aandacht voor een brede benadering van problemen.

'Het lichamelijke pad is heel goed ontwikkeld door de klinische evidence-based Standaarden van het NHG, maar het psychosociale pad is een beetje achtergebleven. Deze modellen helpen om meer naar de hele mens te kijken.' (HA 7)

De zelfredzaamheidsmatrix was bij geen van de geïnterviewde huisartsen bekend. Na uitleg hierover leek het hen wel een goed model voor de praktijkondersteuner-ggz (poh-ggz).

'Het [de zelfredzaamheidsmatrix] lijkt me een mooi framework om twee redenen. Ten eerste dat de poh-ggz naar al die terreinen kijkt. Ten tweede dat het goed zal werken bij patiënten door bijvoorbeeld zo de hoofdpijn te bespreken: 'U hebt natuurlijk schulden, ruzie met uw moeder en u woont niet fijn.' Het werkt goed als mensen merken dat jij ook van die andere terreinen weet hebt.' (HA 1)

\section{De rol van de huisarts}

De huisartsen zagen voor zichzelf een coördinerende en verbindende rol weggelegd bij mensen met sociale problemen. Zij noemden zichzelf vaak 'de spin in het web'. Zij bedoelden hiermee dat zij meestal degene zijn die de patiënten naar verschillende hulpverleners (bijvoorbeeld het sociaal wijkteam, de thuiszorg en dergelijke) verwijst, in de gaten houdt of de verwijzing tot stand komt en het eerste aanspreekpunt is voor de andere betrokken hulpverleners, de patiënt en diens omgeving. Zij bepaalden vaak op welk terrein als eerste hulp gezocht werd.

'Je moet het domein aanpakken waar het grootste probleem ligt.' (HA 1)

Daarnaast wilden zij hun patiënten informeren en bewustmaken van de relatie tussen psychosociale problemen en hun klachten.

Ze zagen zichzelf als poortwachter voor alle soorten zorg en als vertrouwenspersoon en gids voor de patiënt.

'Ik wil het probleem samen met mijn patiënt ontrafelen, helder krijgen hoe het probleem tot behapbare stukjes kan worden teruggebracht en zoeken naar een zorgverlener voor elk van die stukjes.' (HA 11)

Alle huisartsen waren het er over eens dát zij een rol spelen bij het vaststellen van problemen, adviseren en verwijzen van patiënten, maar verschilden van mening over de omvang van die rol en de mate waarin zij zelf actief betrokken willen zijn. De meesten vonden dat hun rol zich beperkt tot het boven tafel krijgen van de problemen en vervolgens verwijzen. Er was één huisarts uit een achterstandswijk die zijn rol breder zag. Hij gaf aan dat hij heel veel zelf doet voor zijn populatie:

'Ik vervul de rol van psycholoog, maatschappe-

lijk werker, financieel adviseur, advocaat, jurist,

relatietherapeut en vader.' (HA 10)

Tijdgebrek was de belangrijkste reden voor de huisartsen om een minder actieve rol te spelen dan ze eigenlijk nodig vonden.

'Ik denk dat je geen tijd hebt om alle problemen te bespreken.' (HA 11)

\section{Samenwerkingspartners}

Alle twaalf huisartsen gaven aan dat de poh-ggz en de wijkverpleegkundige een belangrijke rol spelen in de zorg voor sociaal kwetsbare patiënten. Samen met hen ontwikkelden ze hun eigen sociale kaart van lo- 
kale samenwerkingspartners op het gebied van psychosociale problemen.

'Wijkverpleegkundigen zijn de ogen en oren op somatisch en psychosociaal gebied. Zij hebben een duidelijke signalerende en sociale functie voor patiënten.' (HA 6)

'Mijn praktijk hier op het platteland is heel anders dan stadspraktijken. Mijn patiënten trekken niet aan de bel - dat is ons grootste probleem. Je moet echt zelf opletten of het wel goed gaat met een patiënt. Daarom hebben we een poh-ggz die mensen thuis bezoekt om te checken hoe het met hen gaat. Daarom ook is de samenwerking met de thuiszorg hier zo goed. Als zij contact opnemen, dan weet je dat er iets aan de hand is.' (HA 8)

De respondenten hadden wisselende ervaringen met het sociaal wijkteam, dat vooral in de steden actief is. Bij de oprichting van deze teams was het lang onduidelijk welke zorgverleners ertoe behoorden. Bovendien werken de meeste teams niet zo proactief als de huisartsen zouden willen. In sommige steden waar al enige tijd ervaring was met het sociaal wijkteam hadden de huisartsen ook wel positieve ervaringen omdat hun patiënten daar goed terecht konden voor hun psychische en sociale problemen. In gemeenten zonder sociaal wijkteam verwezen de huisartsen hun patiënten met sociale problemen naar het maatschappelijke werk.

Alle twaalf huisartsen vertelden dat ze heel weinig contact hadden met de gemeente, ook al erkenden zij het belang van gemeentelijke instanties voor patiënten met sociale problemen, zoals de schuldhulpverlening. De meerderheid van de huisartsen vond de gemeente te groot en te ver af staan van de patiënten.

\section{Het belang van integrale zorg}

Alle twaalf huisartsen kenden de term 'integrale zorg'. Zij legden deze als volgt uit: mensen met meerdere problemen op verschillende terreinen hebben ook op al die terreinen hulp nodig die de huisarts niet alleen kan bieden, maar waarvoor meerdere disciplines nodig zijn.

$\mathrm{Zij}$ vonden hun rol in de integrale zorg vanzelfsprekend (zoals hierboven beschreven), en waren blij dat hiervoor vanuit andere disciplines de laatste jaren steeds meer aandacht was. Als voorbeeld hiervan noemden meerdere huisartsen 'Welzijn op recept' [24], de mogelijkheid om patiënten met psychosociale problemen te verwijzen naar een 'welzijnscoach'. Deze coach ondersteunt mensen om gezonder en gelukkiger te leven door bijvoorbeeld vrijwilligerswerk te gaan doen, samen met anderen te eten of te gaan sporten met de buurtsportcoach. De huisartsen die ervaring hadden met 'Welzijn op recept' beschreven dat hiermee een goede verbinding tot stand komt tus- sen zorg en welzijn. Ook hun patiënten waren heel positief over 'Welzijn op recept'.

'Wij lossen problemen op een medische manier op, ook angst of eenzaamheid. We hebben de neiging pillen voor te schrijven, terwijl je juist mensen op een andere manier moet stimuleren om sociale contacten te leggen' (HA 6)

\section{Belemmeringen en voorwaarden om integrale zorg te leveren}

Veruit de meeste huisartsen waren van mening dat 10 minuten veel te kort is voor een consult met een patiënt met een lage sociaaleconomische status, en zeker om sociale problemen boven tafel te krijgen. Eén huisarts had een afwijkende mening en zei dat hij die 10 minuten niet zo'n probleem vond, omdat je met een patiënt meerdere 10-minutenconsulten kunt plannen. Volgens hem hoef je niet alle problemen in het eerste consult te bespreken, maar kun je patiënten ook vragen terug te komen.

De andere huisartsen reserveerden vaak meer tijd bij bepaalde patiënten. Daartoe maakten zij in het dossier een pop-up dat ze meer tijd nodig hebben. Vaak wisten hun assistentes wie een dubbel consult nodig heeft.

Desondanks noemden alle huisartsen tijdgebrek als de belangrijkste reden om niet zo vaak als zij zouden willen integrale zorg te leveren. Niet alleen vanwege de korte consultduur, maar ook vanwege de hoeveelheid tijd die samenwerking kost, bijvoorbeeld bijeenkomsten met het sociaal wijkteam of andere multidisciplinaire overleggen.

Alle huisartsen benadrukten de noodzaak om hun communicatie en voorlichting aan te passen voor achterstandsgroepen die vaak beperkte gezondheidsvaardigheden hebben. Zij gebruikten daarvoor websites als huisarts-migrant.nl en begrijpjelichaam.nl.

De meeste huisartsen gaven daarbij overigens aan dat zij zich onvoldoende toegerust voelden voor de communicatie met laaggeletterde patiënten, en bij sommige migranten moeite hadden met de taalbarrière.

Een ander probleem was volgens alle huisartsen dat de moderne samenleving te sterk uitgaat van het vermogen van burgers om hun eigen problemen op te lossen. Zij waren bezorgd dat mensen met een lage sociaaleconomische status steeds meer uitgesloten raken.

'Ik denk dat je een hogeschooldiploma nodig hebt om te overleven in Nederland, om je inkomen te organiseren, je zorgverzekering, enzovoort. Heel wat mensen raken hierin verstrikt.' (HA 6)

Als voorwaarden voor goede samenwerking noemden de huisartsen korte lijnen en liefst persoonlijk contact. Allemaal vonden ze dat in het algemeen 
nog meer aandacht, tijd en opleiding nodig waren om goede integrale zorg te kunnen leveren.

\section{De mindset van de huisarts}

De huisartsen vertelden dat zij het nu vanzelfsprekend vonden om aandacht te besteden aan sociale problemen en sociaal kwetsbare groepen, maar dat zij in hun opleiding hier heel weinig over hadden geleerd. Ongeveer de helft van de geïnterviewde huisartsen dacht dat hiervoor in de huidige opleiding wel meer aandacht was, hetgeen bevestigd werd door de geïnterviewde huisarts in opleiding.

'Ik denk dat het echt doordringt tot huisartsen dat we iets moeten met deze problemen.' (HA 4)

\section{Beschouwing}

\section{Belangrijkste bevindingen}

Huisartsen, werkzaam in zeer diverse settingen en populaties, vinden dat aandacht voor sociale problemen onder hun sociaal kwetsbare patiënten een essentieel onderdeel vormt van de huisartsenzorg. Aangezien lichamelijke, psychische en sociale problemen vaak samenhangen, achten zij integrale multidisciplinaire zorg noodzakelijk voor een effectieve aanpak van deze problemen. Ondanks verschillen in opvatting over de mate waarin zij actief willen zijn, zien ze zichzelf als een 'spin in het web' met een coördinerende en verbindende rol. Hun belangrijkste samenwerkingspartners zijn de poh-ggz en wijkverpleegkundige, terwijl de ervaringen met het sociaal wijkteam wisselend zijn. De belangrijkste belemmeringen voor integrale zorg zijn volgens de huisartsen gebrek aan tijd, zowel voor patiëntencontact als voor samenwerking, en gebrek aan vaardigheden om op maat te communiceren met laaggeletterden en migranten.

\section{Vergelijking met eerder onderzoek}

Uit eerder onderzoek is bekend dat een sociaaleconomisch problematisch bestaan ook in Nederland lichamelijke en psychische problemen veroorzaakt [25-28], waarbij het ene probleem vaak het andere uitlokt [4]. Dit leidt tot een vicieuze cirkel waar mensen moeilijk zelfstandig uitkomen. Het gevolg is dat huisartsen een grote diversiteit aan onderling samenhangende problemen zien, vooral bij patiënten met een lage sociaaleconomische status.

Om deze verschillende problemen goed aan te pakken vinden de huisartsen dat een multidisciplinaire, integrale benadering nodig is, die ook volgens de literatuur kan bijdragen aan een grotere rechtvaardigheid en betere gezondheid [29].

De wisselende ervaringen van de geïnterviewde huisartsen met het relatief jonge sociaal wijkteam kwamen ook naar voren in een recente evaluatie van het sociaal wijkteam [30].

Tijdgebrek en gebrekkige communicatievaardigheden zijn bekende obstakels voor goede zorg aan patiënten met een lage sociaaleconomische status. Het is echter uitgebreid aangetoond dat persoonsgerichte zorg, die rekening houdt met de persoonlijke context, ervaringen en mogelijkheden van patiënten, uiteindelijk leidt tot betere gezondheid en bovendien tijdwinst oplevert [31]. Recente experimenten waarin de huisarts méér consulttijd kreeg, gecombineerd met een andere manier van communiceren (meer gericht op wat belangrijk is voor de patiënt, dan op de ziekte), blijken inderdaad te leiden tot meer aandacht voor het sociale domein, en minder medische verwijzingen [32]. Investeren in tijd en communicatievaardigheden betaalt zich dus terug.

\section{Beperkingen van dit onderzoek}

Negen van de twaalf huisartsen werden benaderd vanuit het netwerk van de tweede auteur. Hoewel hierbij bewust gekozen was voor huisartsen met verschillende achtergronden, settingen, populaties en ervaring, zou dit tot bias hebben kunnen geleid. Vandaar dat na de eerste negen huisartsen bewust gezocht werd naar huisartsen buiten dit netwerk. De opvattingen en aanbevelingen van deze huisartsen verschilden echter niet wezenlijk, zodat na de interviews met in totaal twaalf huisartsen geen nieuwe inzichten meer boven tafel kwamen.

Dit onderzoek geeft inzicht in de verschillende opvattingen en ervaringen van huisartsen, maar heeft, zoals passend bij kwalitatief onderzoek, niet de pretentie generaliseerbaar te zijn voor alle huisartsen in Nederland, hoewel de groep geïnterviewde huisartsen zeer divers was.

\section{Aanbevelingen}

Kennis over sociaaleconomische gezondheidsverschillen, integrale zorg, samenwerking en communicatievaardigheden zou meer aandacht moeten krijgen in de opleiding tot huisarts, poh, wijkverpleegkundige en professional in het sociale domein. Om effectieve multidisciplinaire samenwerking te bevorderen verdient het aanbeveling om dit onderwijs voor de verschillende professionals te combineren in het kader van interprofessioneel leren [33].

Daarnaast zijn initiatieven gewenst die gericht zijn op betere samenwerking tussen huisartsen/de gezondheidszorg en gemeentelijke diensten en instellingen, inclusief de sociale wijkteams. Tijd, persoonlijk contact en korte lijnen lijken daarvoor van groot belang.

Omdat gebrek aan tijd momenteel een structureel probleem is [34], kunnen goede integrale zorg en samenwerking alleen gerealiseerd worden wanneer 
maatregelen worden genomen om de tijdsdruk in de huisartsenpraktijk te verminderen.

\section{Conclusie}

Huisartsen beschouwen integrale multidisciplinaire zorg voor mensen met sociale problemen als een essentieel onderdeel van hun werk, en hun rol daarin als coördinerend en verbindend. Zij hebben hiervoor meer tijd nodig, naast scholing in communicatievaardigheden en interdisciplinaire samenwerking.

\section{Literatuur}

1. Marmot M. Social determinants of health inequalities. Lancet. 2005;365:1099-104.

2. Stringhini S, Carmeli C, Jokela M, et al. Socioeconomic status and the $25 \times 25$ risk factors as determinants of premature mortality: a multicohort study and meta-analysis of 1.7 million men and women. Lancet. 2017;389:1229-37.

3. Tobias M. Social rank: a risk factor whose time has come? Lancet. 2017;389:1172-4.

4. Beuningen J van, Witt S de. Eenzaamheid in Nederland. Den Haag: Centraal Bureau voor deStatistiek; 2016.

5. Rademakers J. Gezondheidsvaardigheden: niet voor iedereen vanzelfsprekend. Kennissynthese. Utrecht: NIVEL; 2014.

6. Stichting Lezen \& Schrijven. Feiten \& Cijfers. 2017. https:// www.lezenenschrijven.nl/over-laaggeletterdheid/feitencijfers/. Geraadpleegd op: 30 januari 2019.

7. Centraal Bureau voor de Statistiek. StatLine. Bevolking; generatie, geslacht, leeftijd en migratieachtergrond. Den Haag: CBS. 2018. https://opendata.cbs.nl/\#/CBS/ $\mathrm{nl} /$ dataset/37325/table?ts=1516977367963. Geraadpleegd op: 30 januari 2019.

8. Dahlgren G, Whitehead M. Policies and strategies to promote social equity in health. Stockholm: Institute for future studies; 1991.

9. Brunner E, Marmot M. Social organization, stress and health. Oxford: Oxford University Press; 1999.

10. Blane D. The life course, the social gradient, and health. Soc Determ Health. 1999;2:54-77.

11. Popay J, Kowarzik U, Mallinson S, et al. Social problems, primary care and pathways to help and support: addressing health inequalities at the individual level. Part I: the GP perspective. JEpidemiol Community Health. 2007;61:966-71.

12. Wit R de, Haaren K van, Brekel-Dijkstra C van den. NHGpraktijkhandleiding Samenwerken aan gezondheid in de wijk. Utrecht: NHG/RIVM;2018.

13. Dresden D. Jan De Maeseneer over de sociale verschillen in de gezondheidszorg: 'Iedereen telt mee en heeft recht op zorg. Huisarts Wet. 2018;61:38-40.

14. Ruano A, Furler J, Shi L. Interventions in primary care and their contributions to improving equity in health. Int J EquityHealth. 2015;14:153.

15. Kringos D, Boerma W, Zee J van der, et al. Europe's strong primary care systems are linked to better population health but also to higher health spending. Health Aff. 2013;32:686-94.
16. O'Donnell C, Burns N, Mair F, et al. Reducing the health care burden for marginalized migrants: the potential role for primary care in Europe. Health Policy (New York). 2016;120:495-508.

17. Muijsenbergh M van den, Oosterberg E. Zorg voor laaggeletterden, migranten en sociaal kwetsbaren in de huisartsenpraktijk. Utrecht: NHG/Pharos; 2016.

18. Eusman JP, Langen P van, Vroome MCG de. Recept voor hulpverlening. Een onderzoeknaardebehoeftenvanbewonersvan achterstandswijken ten aanzienvan dehuisartsenzorg op sociaal-maatschappelijkgebied. AOF:Amsterdam; 2011.

19. Beenackers M, Nusselder W, Oude Groeniger J, et al. Het terugdringen van gezondheidsachterstanden: een systematisch overzicht van kansrijke en effectieve interventies. Rotterdam: Erasmus MC Universitair Medisch Centrum Rotterdam;2015.

20. Sok K. Samenwerken in de wijk. Movisie: Utrecht; 2013. https://www.nji.nl/nl/Download-NJi/(322206)-samenwerkenindewijk.pdf.

21. Wiersma D. Het 4 Domeinenmodel. Utrecht: Stichting Overvecht Gezond; 2015. http://www.overvechtgezond. $\mathrm{nl} /$ files/Het\%204D-model\%20-\%20Volte.pdf.

22. Huber M. Alles is gezondheid ... Utrecht: Alles is gezondheid. 2018. http://www.allesisgezondheid.nl/content/ positieve-gezondheid. Geraadpleegd op: 30 januari 2019.

23. GGD Amsterdam en Gemeente Rotterdam. Zelfredzaamheid-Matrix. Amsterdam: GGD Amsterdam. 2017. https:// www.zelfredzaamheidmatrix.nl/. Geraadpleegd op: 30 januari 2019.

24. Heijnders ML, Meijs JJ, Groot CM de. Welzijn op recept: een duwtje in de rug bij het weer aangaan van sociale contacten. Kwalitatief deelonderzoek. Bijblijven. 2015;31:926-34.

25. Centraal Bureau voor de Statistiek. StatLine. Diabetes. Den Haag: CBS. 2018. http://statline.cbs.nl/ Statweb/publication $/ ? \mathrm{DM}=\mathrm{SLNL} \& \mathrm{PA}=83005 \mathrm{NED} \& \mathrm{D} 1=3-$ $5 \& \mathrm{D} 2=\mathrm{a} \& \mathrm{D} 3=0 \& \mathrm{D} 4=1 \& \mathrm{VW}=\mathrm{T}$. Geraadpleegd op: 30 januari 2019.

26. Boerdam A. Astma en COPD in beeld. Den Haag: Centraal Bureau voor de Statistiek; 2016.

27. Ujcic-Voortman J, Schram M, Jacobs-van der Bruggen M, et al. Diabetes prevalence and risk factors among ethnic minorities. Eur J Public Health. 2009;19:511-5.

28. Bindraban N, Valkengoed Ivan, MairuhuG, etal. Prevalence of diabetes mellitus and the performance of a risk score among Hindustani Surinamese, African Surinamese and ethnic Dutch: a cross-sectional population-based study. BMCPublic Health. 2008;8:271.

29. MaeseneerJ de. Dehuisarts in maatschappelijkperspectief: Frans Huygen-lezing. Huisarts Wet. 2008;51:485-8.

30. Kok E, Briels B. Evaluaties van sociale wijkteams. Inventarisatie van afgesloten onderzoeken van sociale wijkteams. Utrecht: Movisie; 2014.

31. Levinson W, Gorawara-Bhat R, Lamb J, et al. A study of patient clues and physician responses in primary care and surgical settings. JAMA. 2000;284:1021-7.

32. Nyst E. Bruins bezoekt huisarts Jung in Afferden. Medisch Contact, 22 juni 2018. 2018.

33. Scherpbier-de Haan N. Community of practice: leren dicht bij huis. Huisarts Wet. 2017;60:584-5.

34. KalsbeekE. Nu is de tijd om te investeren. Medisch Contact, 10 mei2017. 2017. 